\title{
3 Research Square

\section{Ethnozoological Study of Traditional Medicinal Animals and Their Products Used by The People of South Achefer District, Northern Ethiopia}

Misganaw Genet Mola ( $\sim$ misganawmola@gmail.com )

Mizan-Tepi University

Yibelu Yitayih Hailie

Mizan-Tepi University

Hailu Birhanie Terefe

Bule Hora University

Reta Yeshambel Kessete

Debremarkos university

\section{Research}

Keywords: Ethnozoology, South Achefer, Zootherauptics, Animal product

Posted Date: September 4th, 2020

DOI: https://doi.org/10.21203/rs.3.rs-70890/v1

License: (c) (i) This work is licensed under a Creative Commons Attribution 4.0 International License.

Read Full License 


\section{Abstract}

Background: There is an ancient history that human beings are familiar with use of animals and plants for food, cloth, medicine, etc. In Ethiopia, many ethnic communities which are dispersed all over the country has been totally dependent on local traditional medicinal system for their health care. Thus, the aim of this study was to take an ethnozoological field survey among different ethnic groups that live in South Achefer district. In order to document the ethno zoological information about animal and their parts/ products prevalent among the people in South Achefer district, a study was carried out from September, 2019 to January, 2020.

Methods: Data was collected through questionnaire, focus group discussion and semi-structured questionnaire with 64 purposively selected respondents.

Result: Ethnozoological data was recorded local name of the animals, animal products used, mode of preparation and administration Based on the ethno zoological survey, a total of 30 animal species were used in 42 different medicinal purposes including cold, night blindness, cough, paralysis and rheumatism and for other religious/and spiritual purposes. Based on the ethno zoological survey, 11 mammals, 7 birds, 4 reptile, 5 arthropods, 2 fish, 1 annelids are used in traditional zootherauptics in the study area. Furthermore, the milk of goat used to relieved cough has the highest FL (92\%) and elephant teeth has the lowest FL (22\%) used to treat bad spirit.

Discussion: The results showed that ethno zoological practices have been an important alternative medicinal practice for the people residing in the study area. So, there is an urgent need to properly document to keep a record of the ethno zoological knowledge of the area. It is hoped that this information will be useful for further research in the field of ethno zoology, ethno pharmacology and conservation point of view.

\section{Background}

Ethiopia has diverse sets of ecosystems that supporting a wide variety of life forms [1]. The country is rich in its faunal diversity and as a result, over 320 species of mammals, above 860 species of birds, 200 species of reptiles, 63 species of amphibians and 145 species of fish are known [2]. Of these faunal species some are importance for treating human and livestock health problems. There is evidence that human beings are familiar with use of animals and plants for food, cloth, medicine, etc., [21].

Traditional Medicine has been practiced for several thousand years ago in different parts of the world particularly where large ethnic communities live in. Currently, more than $80 \%$ of the world population uses traditional medicine either on its own or as a complementary medicine [9]. More than $80 \%$ of the population in Sub-Saharan Africa relies on traditional medicines and Traditional Health Practitioners (THPs) as the primary source of health care [10]. Like in many other developing countries, more than $70 \%$ of human and $90 \%$ of livestock population primarily depend on traditional medicine in Ethiopia [3]. Since 
ancient times, animals and their products have been used in the preparation of traditional remedies in various cultures [4].

Wild and domestic animals and their by-products such as hooves, skins, bones, feathers and tusks are important ingredients in the preparation of curative, protective and preventive medicine [5].

An estimate from the world health organization indicated that about $80 \%$ of the world populations depend primarily on animal and plant based medicines [6].

Ingredients sourced from wild plants and animals are used in traditional medicines and as raw materials in the preparation of modern medicines and herbal preparations [7]. Zootherapy is defined as healing of human ailments by using medicines prepared from different animals and/or animal derived byproducts [8]. Zootherapy constitutes a significant substitute among many other known therapies practiced worldwide [9].

Zootherauptics which refers to the healing of human ailments by using therapeutics based on medicine obtained from animals themselves or ultimately derived from them/or and their parts [11]. In modern society also traditional medicinal knowledge constitutes an important alternative in health care system.

Ethiopia has ancient history in ethno zoological studies and zootherauptic investigations. But there is a limited study in general and Amhara region in particular compare to its faunal diversity. In south Achefer district there are numerous traditional healers that have a great accessibility than modern Hospitals and clinics. But the limitation of documentation of these indigenous knowledge on the study area has a negative impact and makes a gap on knowledge transfer. Therefore, this study is aimed to documentation of ethnozoology and preparations of animals and its products as traditional medicine used to cure different animal ailments in South Achefer district, Northern Ethiopia.

\section{Methods}

\section{Study area description}

The study was conducted in South Achefer woreda in the Amhara National Regional State. South Achefer is one of the Woredas in the West Gojjam zone, bordered by Awi zone in the southern and western, North Achefer in the northern and Lesser Abay river in the eastern boundary. According to the 2007 national census the woreda was estimated to have 160,635 of total population, of which 81855 were males and 78780 were females which settled on $1185.05 \mathrm{~km}^{2}$ area of land. The woreda is divided in to 20 administrative kebeles 2 urban and the remaining 18 are rural in character (South Achefer bureau of Finance and Development).

\section{Selection of study sites}

Preliminary survey was carried out in September, 2019 to collect information about study sites, availability of traditional healers, and topography (accessibility) of the study area. Additional information 
about the area was gathered from the local people. The study was conducted in eight kebeles of south Achefer woreda (Kurbha,Lalibela ,Korench,Care,Lihudi,Ashuda,Chaba and Azena ). These kebeles were purposively selected based on the availability of many traditional healers.

\section{Sampling and data collection}

Data on fauna-based trado-medicinal practice (local name of animals or/and their parts, mode of preparation and administration) were collected through semi-structured questionnaire, interviews and focus group discussion with selected residents of South Achefer district from September, 2019 to January, 2020. 64 selected respondents ( 45 men and 19 women), were used to collect information about traditional knowledge regarding use of animals and their products used in traditional zootheauptics. These respondents were local herbalists, healers, farmers and church intellectuals ("debtera") between 31-69 age groups. The informants were selected based on their experience, recognition as traditional healer, knowledge of healing practice and age. Ethno-zoological data were collected using semi-structured questionnaires. The questions were prepared in English, translated into a local language and administered through interviews. For each ethnozoological medicine, the target groups were asked to explain its therapies, preparation methods, diseases claimed to be treated, parts of animals used, routes of administration, and the local name of the species. The information regarding the use of a particular animal for a specific disease was treated as one user report.

\section{Animal specimen collections and identification}

The local names and associated attributes of medicinal animals were recorded for each of the species. The specimens with its common name, photograph, dead skin, hair, fur, and some products were collected and taken to Bahir Dar University (BDU) for further confirmation.

\section{Data analysis}

For the data analysis, Fidelity Level (FL) which demonstrates the percentage of respondents claiming the use of a certain animal for the same major purpose was calculated. Fidelity Levels (FL) is determined to identify the most important species (animal and/or their product used to treat a particular ailment. These values were calculated as follows [12]

$$
\mathrm{FL}=\mathrm{SF} / \mathrm{TF} * 100
$$

where,

SF : Frequency of citation of a species for a specific ailment

TF : The total number of citations of that species

SF is the number of informants that claim a use of a specific animal species to treat a particular ailment and TF is the total number of the informants who utilized the animals as a medicine to treat any given disease. 


\section{Results}

This study revealed that the traditional medicinal knowledge of treating various kinds of ailments using different animals and their parts/products by local inhabitants of different kebeles of South Achefer district. Most of the people were lack formal schooling education. From the total respondents 49 of the respondents were illiterate and the remaining 15 are educated. Additional Socio-demographic characteristics of the respondents such as sex, age, educational level, and marital status were collected and presented (Table 1).

Information that are collected by questioner with close ended questions about respondents are also incorporated (Table 2). Informants who practice Animal derived traditional medicine to treat ailments inherited the from their family (54\%), from books (5\%) and from surrounding community (16\%). Moreover, $25 \%$ of the informants inherited the animal traditional knowledge from experience. Informants are willing to inherit the knowledge of animal traditional medicine to their children (61\%), to their families (31\%) and to the community ( $8 \%)$. Traditional healers in Ethiopia held their indigenous knowledge in secret [13] and showed interest to pass on the animal-derived traditional medicinal knowledge orally only to their eldest son, at their old age [14].

Approximately 30 animals/or and their products were reported to be used in traditional medicine in south Achefer district. Among these, the mammals constitute the highest number of animal parts or/and their products $11(37 \%)$, followed by birds $7(23 \%)$ used for fauna based trado-medicinal practice. Furthermore, $5(17 \%)$ arthropod group have been reported to be used in the ethno zoological practice of the study area. The remaining animal groups reptiles and fish have the least rank $4(13 \%)$ and $2(7 \%)$ of each respectively and annelids have the most least rank $1(3 \%)$ in the fauna-based trado-medicinal practice of South Achefer district (Fig. 1).

The animals were used as whole or their products like milk, blood, organ, flesh, teeth, and honey for the treatment of various ailments. In addition to this the excreta and urine of some animals were used as traditional medicine in the community (fig .2).In this study 17 parts/products of animals was widely used in traditional medicine, followed by visceral organs, excreta and meat( 6 for each). Others like whole body and bone are least reported medicinal groups.

Traditional medicines are different in their modes of application. Most of the medicines are applied by Eating orally (13 of applications), followed by drinking orally and massaging dermally (6 of applications). Others modes of application like tying, bathing, fumigation and heating were the least modes of application (Fig 3).

Many of the animals were used for the treatment of multiple ailments singly or in combination with other animal products and their parts were found to be used for the treatment of around 42 different kinds of disease including rheumatism, malaria, wart, bad sprit, headache, rabies, anemia, trachoma, gastritis, asthma, paralysis, and cough (table 3). 
Fidelity levels $(\mathrm{FL})$ showed that the percentage of respondent's claiming the use certain body part/product animals for the same specific disease. The goat (Capra aegagrus hircus) milk used to relieve cough had the highest FL $(n=52,92 \%)$ followed by honey of honey bee (Apis mellifica) to treat diarrhea $(n=57,89 \%)$, excreta of hyena to treat evil eye $(n=53,83 \%)$ and the skin of hyena treat from bad sprit $(n=49,76 \%)$. On the other hand, the teeth of elephant (Elephas maximus) to cure bad sprit $(n=$ $14,22 \%$ ), and the spine of porcupine (Hystrix spp.) to cure wound and whole body of lizard (Lacertilia $s p p$.) to cure anemia $(\mathrm{n}=18,28 \%)$ have the lowest fidelity level (table 3$)$.

\section{Discussion}

The choice of species utilized in fauna-based traditional medicinal preparations were found to be guided by many factors. Which in addition to the bioactive constituents, also include some morpho physiological characteristics and behavioral ecology of the animal as well as some mythological conceptions associated with the animal [22]. Ethiopian was not without native doctors, called Hakims whose skillful use of herbs plus faith cured many patients for centuries. Such Knowledge and skill does exist till these days. In Ethiopia, $70 \%$ of human and $90 \%$ of livestock population depend on traditional medicine [15]

In the present study 30 species of animals and/or body parts are reported as zootherapy. These animals play the major role in treating specific disease in local community of South Achefer district. The study conducted by Kindie et a/documented 53 species of animals and their body parts used for treat 36 aliments .Other study conducted by Tsegazeab H.(2012) at Degua tembien,Tigray region recorded 23 species of animals and their body parts/products that used to treat different diseases in the community. Of the total 30 species of animal body parts/products, vertebrates comprised 24 of the total species of animals. They were Fish, birds, reptiles and mammals. The remaining 6 species of animals were invertebrates like arthropods and annelids [16]. As a result animal species that grouped under invertebrate group have low medical importance in the study area. This might be due to cultural ideology of the community. Because eating invertebrates (insects, earthworm, cockroach, mayfly etc.) may not permitted culturally and spiritually.

In this study, parts/products of medicinal animals were grouped under meat/fat, blood, visceral organ, whole body, excreta, bone/teeth, and product categories and these categories were similar to ones reported by Kindie et al [17]. Other researches also stated that wild and domestic animals and their byproducts such as hooves, skins, bones, feathers, and tusks are important ingredients in the preparation of curative, protective, and preventive medicine [18]. This study showed that traditional medicines were administrated by drinking, eating, anointing, tying, branding, fumigation, and massaging. The mode of administration is similar with study of kindie et al at Metema woreda. The study conducted by Gidey Yirga et al. showed most of traditional medicines were administrated orally and through dermal. Fumigating materials such as smokes were also entering into the body using nasal opening to treat different ailments. Some parts of animals such as bones, skin, and teeth were believed to be medicine by tying on the neck or other parts of the body [19]. 
According to Fidelity Level report from respondent's goat milk and honey of Apis mellifica took the highest frequency of use report followed by hyena excreta and honey of stingless bee. The study conducted by kindie et al., reported that high fidelity level on the honey of bee species (Apis mellifera) is known to relieve wart, asthma, diarrhea, throat pain, stomachache, cough, and tuberculosis. On the other hand the teeth of elephant (Elephas maximus) that cure bad sprit and the spine of porcupine (Hystrix spp.) that treat wound have least fidelity level [12].

The finding of this study suggested that the traditional zootherapeutic remedial measures followed by the native people of South Achefer district plays an important role in their primary health care. The district is biodiversity rich area especially in faunal resource. The documentation of this indigenous knowledge on animal-based medicines should be very helpful in the formulations of strategies for sustainable management and conservation of bio-resource as well as providing potential for novel drug discoveries [20].

\section{Conclusion}

Ethiopia is rich in biological resources and home to different ethnic groups, many of which have adopted various techniques to protect their health care systems and uses traditional medicine derived from plants and animals. Animal derived medicines are an alternative to treat ailments in rural areas. Thus, results of this study revealed that 39 parts and/or products of 30 animal species were used as a traditional medicine to treat different ailments in the study area. Moreover, this study recorded the most popular animal derived medicine to cure various ailments. Most of the users this knowledge were rural residents. Also urban dwellers are recorded as users of this traditional animal products.

\section{Declarations}

We approve that this work is original and has not been published elsewhere, nor is it currently under consideration for publication elsewhere.

\section{Availability of data and materials}

The data used and analyzed during the current study is available in the hand of corresponding author for further request if request is available from reviewers without disclosure of the interviewees.

\section{Funding}

Not funding available

\section{Authors' contributions}

$\mathrm{MM}, \mathrm{YY}, \mathrm{HB}$ and $\mathrm{RY}$ proposed the research idea and collected the data from the respondents. MM organized the data in computer, did the analysis, interpretation, and identification, and wrote the 
manuscript. $\mathrm{YY}, \mathrm{HB}$ and $\mathrm{RY}$ revised the manuscript for scientific content and did the language check. All authors read and approved the final manuscript.

\section{Ethics approval and consent to participate}

Permission to conduct the ethonozoological study was obtained from district administrators and kebele leaders in the study area. The purpose of study was explained for all informants and they agree to give their indigenous knowledge.

\section{Consent for publication}

This manuscript does not contain any individual person's data, and further consent for publication is not required.

\section{Conflict of interest}

On the behalf of all authors there is no conflict of interest.

\section{References}

1. EWNHS (Ethiopian Wildlife and Natural History Society (1996). Important Bird Areas of Ethiopia: A First Inventory report. Addis Ababa.pp.300

2. Afework Bekele and Yalden, W. (2013). Mammals of Ethiopia and Eritrea. Addis Ababa University Press, Addis Ababa.

3. Endashaw, B.: Study on Actual Situation of Medicinal Plants in Ethiopia. Japan Association for International Collaboration of Agriculture and Forestry (JAICAF) (2007).

4. Lev, E. and Z. Amar, Ethnopharmacological survey of traditional drugs sold in Israel at the end of the 20th century. J. Ethnopharmacol., 72(1-2): 191-205.

5. Adeola, M.O.: Importance of wild Animals and their parts in the culture, religious festivals, and traditional medicine, of Nigeria. Environmental Conservation (1992) vol 19(2):125-134.

6. WHO/IUCN/WWF, 1993. Guidelines on Conservation of Medicinal Plants. Switzerland,

7. Kang SP. Question of attitude: South Korea's traditional medicine practitioners and wildlife conservation. Hong Kong: TRAFFIC East Asia; 2003.

8. Costa-Neto EM. Healing with animals in Feira de Santana city. Bahia Brazil J Ethnopharmacol. 1999;65:225-30.

9. Boakye, M.K., Pietersen, D.W., Kotzé, A., Dalton, D.L., Jansen, R.: Knowledge and Uses of African Pangolins as a Source of Traditional Medicine in Ghana.PLoS ONE: (2015) vol 10(1)

10. Keter, L.K., Mutiso, P.C.: Ethno botanical studies of medicinal plants used by Traditional Health Practitioners in the management of diabetes in Lower Eastern Province: Kenya.Journal of Ethno pharmacology (2012) vol 139: 74-80. 
11. Solvan, , R. Paulmurugan, V. Wilsanand and S. Ranjith, 2004. Traditional therapeutic uses of animals among tribal population of Tamil Nadu. Indian J. Tradit. Knowl., 3(2): 198-205.

12. lexiades, M.N., 1996. Selected Guidelines for Ethnobotanical Research: A Field Manual. New York Botanical Garden, Bronx, pp: 306, ISBN: 0893274046.

13. Samuel, Z., Gidey, Y.: Traditional knowledge of medicinal plants in Gindeberet district, Western South Afr. J. Bot. (2012) vol 78:165-169.

14. Jansen, P.C.M.: Spices, Condiments and Medicinal Plants in Ethiopia: Their Taxonomy andAgricultural Signi cance. College of Agriculture, Addis Ababa University, Ethiopia and the Agricultural University, Wageningen, the Netherlands, Centre for Agricultural Publishing and Documentation, Wageningen (1981).

15. Birhanu Z. Traditional use of medicinal plants by the ethnic groups of Gondar Zuria District, NorthWestern Ethiopia. J Nat Rem. 2013;13(1):2320-3358.

16. Chakravorty J, Meyer-Rochow VB, Ghosh S. Vertebrates used for medicinal purpose by members of Nyishi and Galo tribes in Arunachal Pradesh (North-East India). J Ethnobiol Ethnomed. 2011;7:13.

17. Kindie et al ., Ethnozoological study of traditional medicinal appreciation of animals and their products among the indigenous people of Metema Woreda, North-Western Ethiopia J Ethnobiol Ethnomed. 2018;14:37.

18. Costa-Neto, E.M.: Animal-based medicines Biological prospection and the sustainable use of zootherapeutic resources. Ann. Acad. Bras. Cienc (2005) vol 77(1): 33-43.

19. Jaroli DP, Mahawar MM, Vyas N. An ethnozoological study in the adjoining areas of Mount Abu wildlife sanctuary, India. J Ethnobiol Ethnomed. 2010;6:6.

20. Borah MP, Brasad SB. Ethnozoological study of animals based medicines used by traditional healers and indigenous inhabitants in the anointing area Gibbon Wildlife Sanctuary, Assam, India. J Ethnobiol Ethnomed. 2017;13:39.

21. Judith, H., 2005. Information Resources on HumanAnimal Relationships Past and Present. Animal Welfare Information Center, Resource Series No. 30.

22. Tsegazeabe H. Haileselasie,2012. Traditional Zootherapeutic Studies in Degu'a Tembien,Northern Ethiopia . Current Research Journal of Biological Sciences 4(5): 563-569.

\section{Tables}


Table 1

Socio-demographic characteristics of the informants in the study area (n $=64$ )

\begin{tabular}{|lll|}
\hline Basic information & Number of respondents & Percentage (\%) \\
\hline Sex & 45 & 70 \\
Male & 19 & 30 \\
\hline Female & & \\
Age & 20 & 31 \\
$31-45$ & 31 & 49 \\
$46-55$ & 13 & 20 \\
\hline$>56$ & & \\
\hline Educational background & 49 & 76 \\
\hline Illiterate & 49 & 24 \\
\hline Literate & 15 & 53 \\
\hline Marital status & & 28 \\
\hline Married & 34 & 19 \\
\hline Single & 18 & \\
\hline Divorced & 12 & \\
\hline
\end{tabular}


Table 2

Information that was acquired by close-ended questionnaire

\begin{tabular}{|c|c|c|c|c|}
\hline No. & Questions & Alternatives & $\begin{array}{l}\text { No. of } \\
\text { respondents }\end{array}$ & $\begin{array}{l}\text { Percentage } \\
(\%)\end{array}$ \\
\hline \multirow[t]{4}{*}{1} & \multirow{4}{*}{$\begin{array}{l}\text { What is the source of your medicinal } \\
\text { knowledge? }\end{array}$} & A) Family & 35 & 54 \\
\hline & & B) books & 3 & 1 \\
\hline & & C) community & 10 & 15 \\
\hline & & D) Experience & 16 & 25 \\
\hline \multirow[t]{4}{*}{2} & \multirow{4}{*}{$\begin{array}{l}\text { Which one is the first selection of people } \\
\text { for healing immediately? }\end{array}$} & \multirow{2}{*}{$\begin{array}{l}\text { A) modern } \\
\text { medicine }\end{array}$} & 31 & 48 \\
\hline & & & 28 & 44 \\
\hline & & $\begin{array}{l}\text { B) tradittonal } \\
\text { medicine }\end{array}$ & 5 & 8 \\
\hline & & C) I do not know & & \\
\hline \multirow[t]{4}{*}{3} & \multirow{4}{*}{$\begin{array}{l}\text { What is your customer satisfaction on your } \\
\text { service? }\end{array}$} & A) Excellent & 4 & 6 \\
\hline & & B) very Good & 8 & 13 \\
\hline & & C)good & 40 & 62 \\
\hline & & D) I do not know & 12 & 19 \\
\hline \multirow[t]{4}{*}{4} & \multirow{4}{*}{$\begin{array}{l}\text { How do you know the dose of your } \\
\text { medicine? }\end{array}$} & A)by measuring & 9 & 14 \\
\hline & & B)by experience & 19 & 30 \\
\hline & & C) by try and error & 28 & 44 \\
\hline & & D) I do not know & 8 & 12 \\
\hline \multirow[t]{4}{*}{5} & \multirow[t]{4}{*}{$\begin{array}{l}\text { For whom do you want to transfer your } \\
\text { knowledge? }\end{array}$} & $\begin{array}{l}\text { A) for all family } \\
\text { member }\end{array}$ & 20 & 31 \\
\hline & & B) for & 5 & 8 \\
\hline & & $\begin{array}{l}\text { surrounding } \\
\text { community }\end{array}$ & 39 & 61 \\
\hline & & $\begin{array}{l}\text { C) for my children } \\
\text { only }\end{array}$ & & \\
\hline \multirow[t]{4}{*}{6} & \multirow{4}{*}{$\begin{array}{l}\text { What was the reason that forces the } \\
\text { people to use traditional medicines? }\end{array}$} & A) accessibility & 18 & 28 \\
\hline & & \multirow{2}{*}{$\begin{array}{l}\text { B) Lack of } \\
\text { modern medicine }\end{array}$} & 10 & 16 \\
\hline & & & 11 & 17 \\
\hline & & D) Economy & 25 & 39 \\
\hline
\end{tabular}




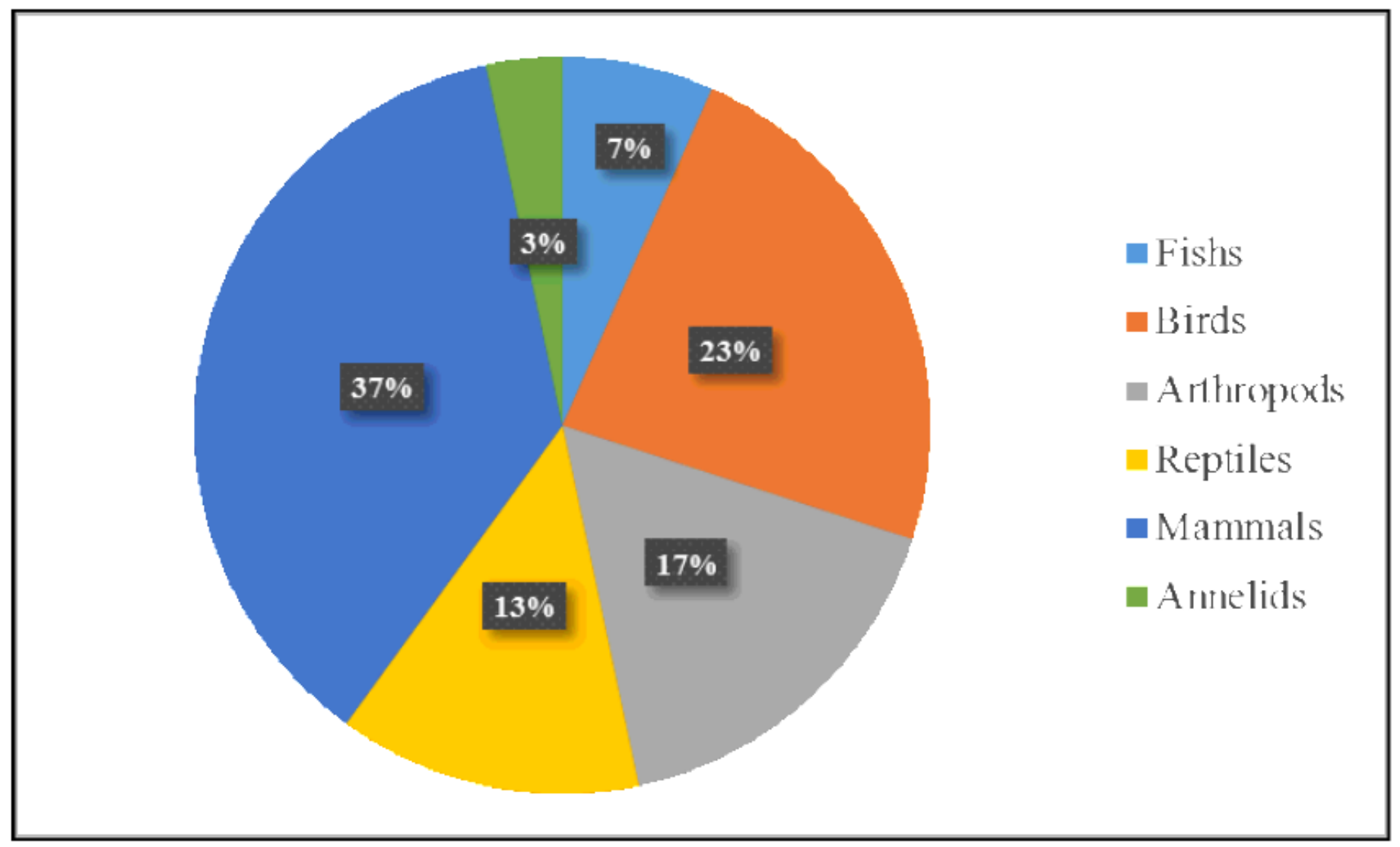

Figure 1

Animal groups and number of species used for traditional medicine in the study area 


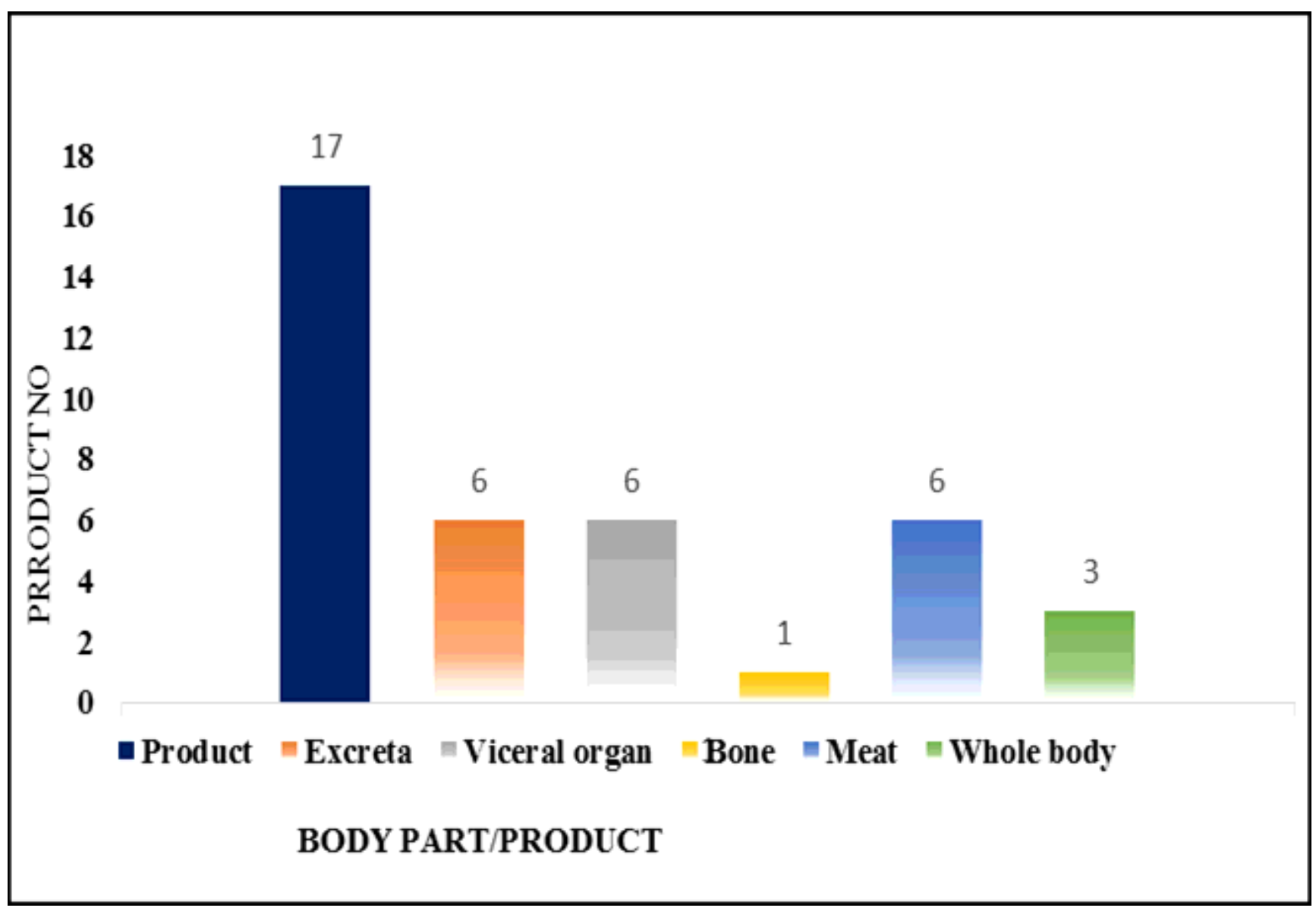

Figure 2

Animal parts or products used to traditional medicine in the study area 


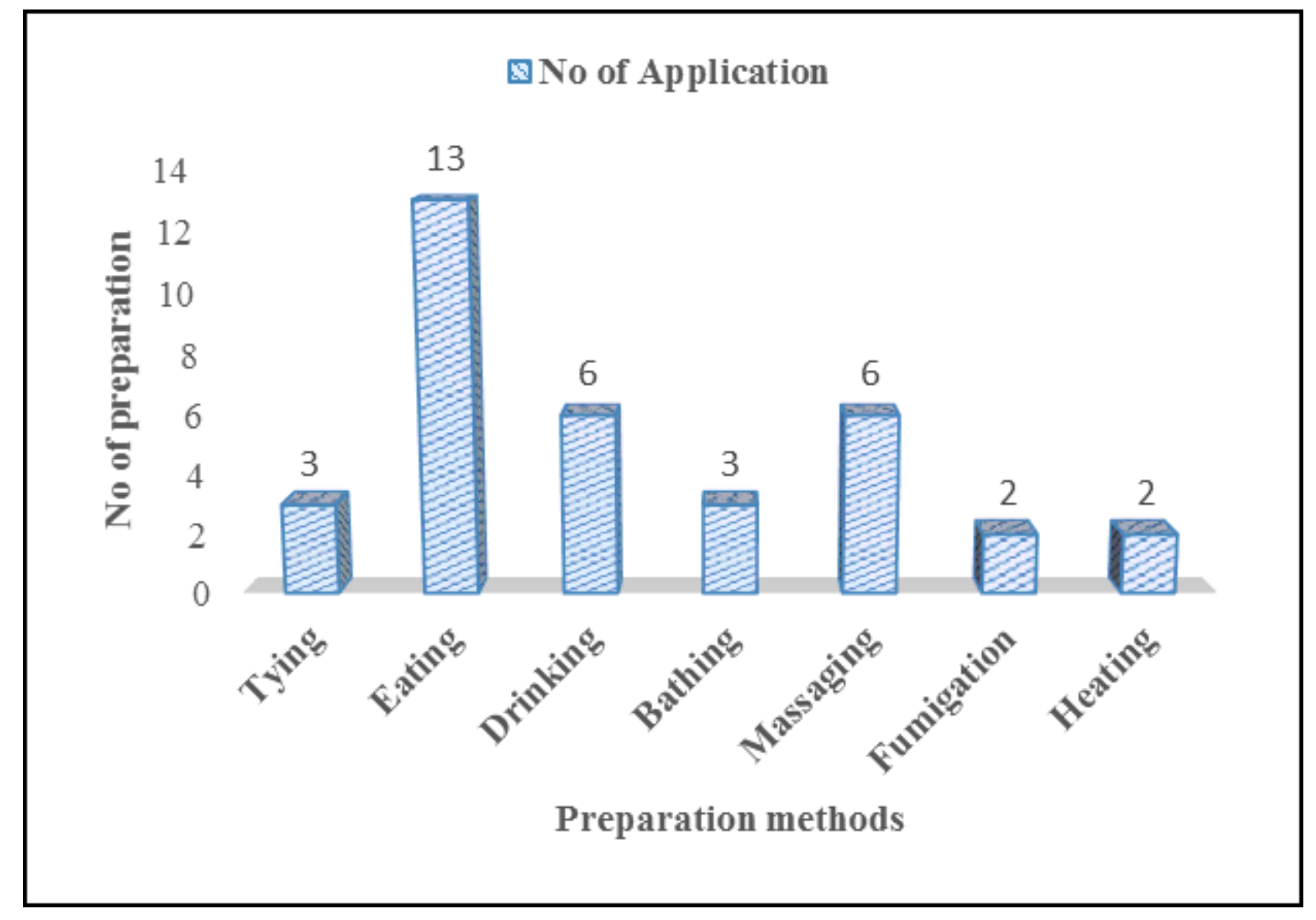

Figure 3

Mode of application/administrations of traditional medicines

\section{Supplementary Files}

This is a list of supplementary files associated with this preprint. Click to download.

- Additionaldata.docx

- Additionaldata.docx 